\title{
Influence of Cyberphobia on Female Undergraduates Participation in Internet Research
}

\author{
${ }^{1}$ Chibueze Offor, ${ }^{2}$ Elochukwu Ukwandu and ${ }^{1}$ Roseline Ogbonna \\ ${ }^{1}$ Department of Psychology, Faculty of Social Science, ${ }^{2}$ Department of Computer Science, \\ Faculty of Science, Evan Enwerem University, Owerri, Nigeria
}

\begin{abstract}
The study examined the Influence of Cyberphobia on Female Undergraduate Participation in Internet Research. The hypotheses tested were: there will be no statistically significant difference in female undergraduate participation in internet research between those who experience Cyberphobia and those who do not, there will be no statistically significant difference in female undergraduate participation in internet research between 100 and 400 level female undergraduates, there will be no statistically significant interaction between Cyberphobia and level of study. Self developed and validated scales were used to elicit information from respondents on their level of Cyberphobia and internet participation. One hundred and ten female undergraduates from Faculties of Business Administration, Health Science, Social Sciences and Education in Evan Enwerem University, Owerri constituted the study sample. The design was a survey correlation while the data collected were analysed using descriptive statistics and two-way ANOVA. Findings showed that female undergraduates with Cyberphobia participate less in internet research than female undergraduate with absence of Cyberphobia. About 100 level female undergraduates participate more in internet research than 400 level female undergraduates. Findings suggest that high cost if internet facilities, elimination of stereotyping and discrimination against females and parental involvement in their children's choice of study were suggested to encourage female participation in internet research.
\end{abstract}

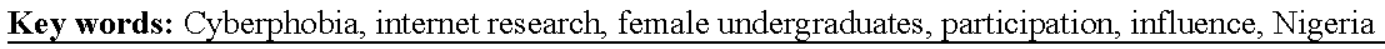

\section{INTRODUCTION}

Internet research in recent times has been seen as a rallying point for faster economic and social development of any nation. This is obvious and quite clear that information from the internet is for everyone and women are equal beneficiary to the advantages offered by it. The product and processes which emerge from their usage are what people need to change their world (Vikas, 2003).

Over the years, the participation of women in iternet research has been a cause for concern because female participation in Nigeria is low (Liverpool, 2004). Internet research enables people to acquire knowledge, especially the youths in higher institutions. This is because they are potential contributors to the global market. They can use the internet to participate in and complete various learning tasks whether formal and informal (Olubamise and Awe, 2007).

But looking at the level of female undergraduates participation in technology and internet in particular, both in developed and developing nations alike, it appears obvious that female students have been lagging behind
(Nwajiuba and Ukwandu, 2007) and this calls for serious concern since, human population is made up of female and male and there is need for full participation of both gender in national development. While increasing statistics are being made available on female use of internet research in developed countries, it is still quite difficult to get reliable statistics in developing countries especially in Nigeria. However, Hafkin and Taggart (2001) as cited in Liverpool and Ajayi affirm that few women participate in internet research in Africa and that internet research is still seen as a man's job in Africa. Liverpool (2004) observed that over the years, there has been a record of low female participation in internet research. The majority of available literature on gender and internet technology, especially in developing countries appears to describe a disturbingly dismal situation as far a female participation is concerned.

Some studies show that there are successful cases of Internet research adoption and use by women not ignoring the many persistent problems which still subsist or exist (Liverpool, 2002). Various factors have been adduced to explain low female participation in internet

Corresponding Author: Chibueze Offor, Department of Psychology, Faculty of Social Science, Evan Enwerem University, Owerri, Nigeria 
research. These include sociocultural role, stereotyping, lack of property ownership being engrossed in domestic chores, lack of relevant models or mentors, socioeconomic facors, family relation, geographic location of Cybercafes', male domination in technology usage, etc. (Opie, 1998; Durnde1l, 1990; Colclough et al., 2000; Nwajiuba and Ukwandu, 2007; Colley, 2003).

However, these factors are basically situation oriented and devoid of relevant personal variables such as cyberphobia hence this research. Cyberphobia refers to irrational fear and apprehension of the computer, typified by excited mood state, sweating on the palms, fidgeting before computer and unconscious avoidance behaviour, etc. What therefore could be done for a level play ground for both genders in terms of internet participation? What are the major consequences of this trend to nation building? These are the questions this study is concerned with. The objectives of this study are:

- To examine reasons for low female participation in internet research

- To examine the influence of of Cyberphobia on low female undergraduate participation in internet research

- To examine the consequences of low female participation in internet research

- To explore ways of encouraging female participation in internet research

\section{Theoretical reviews}

Social Learning theory: B.F. Skinner and other behaviourists have argued that humans and animals learn behaviours only by directly experiencing the rewards or punishments for these behaviours. In the 1950s however, Psychologists Albert Bandura argued that people can also learn behaviours by watching other people, a view that came to be known as Social Learning theory. Four important factors in social learning include observation, models, identification and imitation.

First in modeling, people learn new behaviours from imitating the behaviours modeled by important people in their lives such as the parents, siblings and friends. Learning through modeling is more likely to occur when the person modeling the behaviour is seen as an authority, figure or is perceived to be like oneself. For example, Bandura (1969) argue that children are most likely to imitate the behaviours modeled by their same sex parents because this parent is an authority figure and because their same sex parent seems more similar to them than their opposite sex parent. Observational learning takes place when a person observes the rewards and punishments that another person receives for his or her behaviour and then behaves in accords with those rewards and punishments. For instance, a female child views her elder sister being punished for fiddling with computer parts instead of running house chores like washing, cleaning the house and thus will be less likely to engage in this behaviour herself.

Cognitive theories of phobia: The cognitive theories of phobia have primarily focused on the development of Social phobia (Rapee and Heimberg, 1997; Turner et al., 2002). According to these theories people with social phobia have excessively high standards for their social performance. For example, they may believe that they should be liked by everyone they meet, especially the friends and avoid anything embarrassing in front of others. Unfortunately, they also tend to focus on what is going right and they evaluate their own behaviour extremely harsh. They do not enter social situations assuming that others will find it boring, unattractive, time consuming. People with social phobia also show biases in self-defeating ways (Heinrichs and Hofmann, 2001). They are exquisitely attuned to their own self-presentation and they tend to assume that if they feel anxious, it is because the social interaction is not going well (Clark and Wells, 1995).

Empirical review: A number of empirical studies have indeed demonstrated the evidence of gender disparity in the adoption and use of the internet. In a recent study, the UCLA (2004) (Usability Center Los Angeles) world internet project reported that in the United States, $73.1 \%$ males reported using internet compare with $69 \%$ of their female counterpart. In the same study, $63.9 \%$ of their males in United Kingdom reported using internet compared with $55 \%$ of females. While in Italy, $42 \%$ of males reported using internet compared to $22 \%$ of the females.

Disparity has also been reported on the purpose for which both gender use the internet. Colley (2003) found that boys use the internet mostly for information search, entertainment and leisure activities while girls use the internet predominantly for interpersonal communication. From three schools surveyed in United Kingdom the researcher found that while females prefer the internet for e-mail, male use internet for games and sports. Similar findings were also made in Singapore and Hong Kong suggesting that gender differences in internet use cut across culture or is cross-cultural (Colley, 2003).

Beyond usage, Colley (2003) also found that gender differences also exist for attitudes towards the internet. Girls were found to have less positive attitudes towards the internet than boys. They are more disoriented and 
desenchanted with the world wide web than boys. They have less confidence in their ability to use the internet and are more anxious using it.

Jackson et al. (2001) thus argue that gender differences in internet use can be explained in terms of cognitive, motivational and affective factors. Cooper and Weaver (2003) developed a four interrelated factor model that influence and individual's use of and attitude towards the computer. These are computer identification, computer anxiety, performance attribution and expectation. The crux of this model is that whatever increases a person's computer anxiety will always lead him to doubt his ability and cause him to deidentify with computer and will also result to forming negative attitude which in turn may lead the individual to avoiding activities, contexts and careers involving computers. The current research extends this model of computer use to explore attitudes towards and use of the internet and examines gender influence on internet use.

A number of studies using both Anglo-Americans, Romania undergraduates and an adult internet sample found a negative relationship between computer anxiety and self report of computer use (Jackson et al., 2001; Durndell and Haag, 2002; Barbiete and Weiss, 2004). Chou (2003) using Taiwanese school teachers found statistically significant negative relationship between computer anxiety and number of hours spent on the internet in a week.

On internet identification, Holloway and Valentine (2003) reported a study of 11-16 years old British children. They found that internet identification provided a group of 14 years old boys with social network which they cherish. In constrast, a group of girls who did not identify with the internet were not concerned about their ability to use the internet were not motivated to spend time learning how to use it and were less likely to enrol in courses concerning the internet. Moreover, they were not anxious when they performed badly in internet use because it does not threaten their self esteem.

Economic status of families: The economic status of the family is known to be significantly related to Cyberphobia among female undergraduates in internet research. The direct cost of internet research is buying of a personal computer and access to the internet. Boys dominate in this area because of nature of task division in traditional societies where girls often do more household chores while boys participate in income generating activities. The indirect cost of internet research arises from the labour time for families where their children are in school. While both boys and girls of poor families contribute to household labour and income, girls often are involved in labour at younger age. This is because task division in traditional societies involves girls in household chores and caring for younger siblings rather than part-time jobs.

\section{Hypothesis:}

- There will be no statistically significant differences in female undergraduate participation in internet research between those who experience Cyberphobia and those who do not

- There will be no statistically significant differences in female undergraduate participation in internet research between 100 and 400 level students

- There will be no statistically significant interaction between Cyberphobia and level of study

\section{MATERIALS AND METHODS}

Participants: The participants for the study were 110 in number. About 55 participants were drawn frome ach of 100 and 400 level students from the Faculties of Business Administration, Health Sciences, Social Science and Education of Evan Enwerem University, Owerri. Stratified random sampling techniques was used to select participants for the study. The selection was conducted by using Balloting Method in which Yes and No were written on pieces of papers and passed round off the day's lecture. Those who picked Yes were given the questionnaire to fill while those who picked No were excluded in the research.

Instrument: The instruments employed in this study were scales on Cyberphobia and internet participation. To develop the first instrument, six items where lifted from internet anxiety scale by Joiner et al. (2005) while the researcher suggested the other remaining two items. The second scale is an internet participation scale consisting of 10 items questionnaire developed by the researcher using three point Likert scale of Always, Occasional, Rarely/often.

These questionnaires were designed to elicit responses. Provisions were made for the respondents to fill in their sex, age, level of study, department and marital status in the personal data column. Items of scale A was scored directly $(5,4,3,2,1)$. Items in scale $\mathrm{B}$ were directly scored as $3,2,1$. The norm of scale A was 24 meaning that students who scored one to twenty four do not suffer from Cyberphobia while those who scored $25-40$ are cyberphobic. The norm of scale B was 20 meaning students who score 1-20 do not participate in the internet while students who scored 21-30 participate in the internet. Cyberphobia and internet participation scales were validated through a pilot study with a sample of 20 
participants. Scale A had a Cronbach's Alpha reliability coefficient of 0.981 . This shows that it is very much reliable while scale B had a Cronbach's Alpha reliability of 0.750 which indicated that it is very much reliable. The method used is split half validation method. The 20 participants were made up of 20 female undergraduates from Philosophy and French Departments in Abia State University.

Procedure: The data collected were done by means of the structured questionnaire. The questionnaires were carefully administered directly to the participants in their faculty lecture halls. The participants were randomly selected through balloting to give the participants equal opportunity of being selected. So, those who picked Yes from the basket were used for the study. The minimum age was 17 years and the maximum age was 40 years.

However, the respondents were not compelled to fill the questionnaire but rather the researcher gently sought for their cooperation to fill the questionnaires. At the end, the researcher retrieved the questionnaires from the participants and realized that 110 questionnaires were filled while two were left blank.

Design/statistics: The most appropriate design used for this study was $2 \times 2$ factorial designs and the statistic was two way ANOVA (F-test) (Table 1). Participants without Cyberphobia participated more in internet research than those with Cyberphobia, hence calculated $\mathrm{f}$ of 3.466 was greater than critical $\mathrm{f}$ at $\mathrm{pc}<0.05$. No statistically significant difference was observed between the participantss across levels of study, hence calculated $\mathrm{f}$ of 0.236 was less than critical $\mathrm{f}$ of 0.628 at $\mathrm{pc}<0.05$. Also statistically significant interaction effect between Cyberphobia and level of study was found since, the calculated $f$ of 4.277 was greater than critical $f$ at $\mathrm{pc}<0.05$.

The study investigated the influence of Cyberphobia on female undergraduates' participation in internet research. Three hypotheses were formulated. The first hypothesis maintained that there will be no statistically significant differences in female undergraduates' participation in internet research between those who experience Cyberphobia and those who do not. This hypothesis was rejected as the alternate was accepted because the calculated (F-test) value of 3.466 is greater

Table 1 : Summary of $2 \times 2$ ANOVA

\begin{tabular}{lrrrcc}
\hline Sources & \multicolumn{1}{c}{ SS } & df & \multicolumn{1}{c}{ MS } & Calculated f & Critical f \\
\hline Cyberphobia (A) & 21.791 & 1 & 21.79 & 3.466 & 0.650 \\
Level of study (B) & 1.487 & 1 & 1.49 & 0.236 & 0.628 \\
Interaction (A x B) & 26.889 & 1 & 26.89 & 4.277 & 0.041 \\
Error (SS S/A) & 666.423 & 106 & 6.29 & - & - \\
\hline
\end{tabular}

than the critical value of 0.065 . Female undergraduates with absence of Cyberphobia ( $\overline{\mathrm{X}}=17.955)$ participated more in internet research than those with phobia. The statistically significant differences in participating in internet research are due to irrational fear they encounter during internet research. The study of Opie (1998) is in line with this assertion. He studied many reasons why females develop Cyberphobia; he showed that the history of computing courses in British schools comes out of male dominated technology courses and department with mainly male teachers dominating everything. He also opined that even at home parents buy computers for their male children as reinforcement. So, the female are stereotyped and eventually develops Cyberphobia.

The second hypothesis which assumed that there will be no statistically significant differences in female undergraduates' participation in internet research between 100 level female undergraduates and 400 level female undergraduates. This hypothesis was not rejected because the calculated value of 0.236 is less than the critical value of 0.628 . About 100 level female students with $(\overline{\mathrm{X}}=17,600)$ participates more in internet research than 400 level female students with $(\bar{x}=16,900)$. This is due to the fact that 400 level female students complain of time factor and studies. Also, 400 level female students think that they have arrived and rely more on their personal knowledge than internet while 100 level female students are still new or fresh and are craving for more knowledge. This makes them to participate more.

The third hypothesis, states that there will be non-statistically significant interaction between Cyberphobia and level of study. This hypothesis was rejected due to the fact that the calculated F-test value of 4.277 is greater than the critical value of 0.041 . All these finding indicate that being cyberphobic reduces an individual participation in internet research.

\section{CONCLUSION}

The main aim or the primary purpose of this study was to evaluate the influence of Cyberphobia and level on female undergraduate participation in internet research. The study was conducted with one hundred and ten female participants drawn from 100 level and 400 level from the faculties of Business Administration, Health Sciences, Social Science and Education in Evan Enwerem University Owerri. The analysis carried out from the data collected showed a statistical significant difference in participating in internet research of females who have presence of Cyberphobia and females with absence of Cyberphobia. The study also showed a significant difference in the participation in internet research of 100 
and 400 level. In conclusion, Cyberphobia and level of study had statistically significant influence on female participation in internet research.

The results and the findings of this study show that the state of being cyberphobic limits and reduces an individual's rapour with the internet or reduces an individual's participation in internet research. The second finding implies that 100 level female students indulges or participates more in internet research than 400 level female students. The third implication of this study also indicates that Cyberphobia and level of study had statistical significant influence on female participation in internet research. This study is very important and necessary because it will help in enlightening parents/guardians and teachers on the negative effects of regarding the internet as a male affair thereby causing Cyberphobia for the females.

This study will also help in reawakening and improving the interest of females in participating in internet research because by this study, they will now see it as helpful to everybody not only the males. The study will also help enlighten students on importance of using internet for their researches and work.

\section{LIMITATION}

There were some factors which served as problems, challenges and limitation to the researchers in this study, factors such as finance which was used for the development and for the production of the instruments which weres used. The study was highly demanding as it was very difficult getting into these faculties, let alone getting the female participants which were used in this study. Another limitation was that the school environment where the study was carried out was very noisy and unconducive for the researcher and the students.

\section{RECOMMENDATIONS}

Based on the findings of this study, the researchers hereby recommend that parents, guardians, teachers and even the government should stop or desist from any act of stereotype and discrimination against females. This can be achieved by making sure that females are also exposed to internet facilities early in life just as their male counterparts. Governments can also subsidies the prices of these computers to school so, as to make them affordable and accessible for students use in the schools and homes. School management can also employ and recruit qualified professionals to teach this courses in school which should start from the primary classes. There should be the development and promotion of mentoring programs where women would be trained as instructors and the trainers can serve as models to females. The internet should be gender-friendly, available and enable adaptability. The internet should become women-friendly in terms of cost, access and applicability in different fields. Parental involvements in their children's selection of choice of study were suggested to encourage female participation in internet research.

Researches should be carried out on this topic but when carrying it out, researchers should increase their sample size, select participants from two or more institutions in different localities. Researchers can also include males in their further studies or even study males alone in participating in internet research. Researchers when carrying out this study should ensure that the school environment is free and void of noise and every sort of distractions.

\section{REFERENCES}

Bandura, A., 1969. Social-Learning Theory of Identificatory Processes. In: Handbook of Socialization Theory and Research, Goslin, D.A. (Ed.). Rand McNally, Chicago, pp: 213-262.

Barbiete, F.G. and E.M. Weiss, 2004. Computer selfefficacy and anxiety scales for an internet sample: Testing measurement equivalence of existing measures and development of new scales. Comput. Hum. Behav., 20: 1-15.

Chou, C., 2003. Incidence and correlates of internet anxiety among high school teachers in Taiwan. Comput. Hum. Behav., 19: 731-749.

Clark, D.M. and A. Wells, 1995. A Cognitive Model of Social Phobia. In: Social Phobia: Diagnosis, Assessment and Treatment, Heimberg, R.G., M. Liebowitz, D.A. Hope and F. Schneier (Eds.). Guilford Press, New York, ISBN: 9781572300125, pp: 69-93.

Colclough, C., P. Rose and M. Tembon, 2000. Gender inequalities in primary schooling-The roles of poverty and adverse cultural practice. Int. J. Educ. Dev., 20: 5-27.

Colley, A., 2003. Gender differences in adolescent' perceptions of the best and worst aspects of computing at school. Comput. Hum. Behav., 19: 673-682.

Cooper J. and K.D. Weaver, 2003. Gender and Computers: Understanding the Digital Divide. Taylor and Francis, Mahwah, NJ, ISBN-13: 9780805844269, Pages: 168.

Durndell, A. and Z. Haag, 2002. Computer self efficacy, computer anxiety, attitudes towards the Internet and reported experience with the Internet, by gender, in an East European sample. Comput. Human Behav., 18: 521-535. 
Durndell, A., 1990. Why do female students tend to avoid computer studies? Res. Sci. Technol. Edu., 8: 163-170.

Hafkin, N. and N. Taggart, 2001. Gender, information technology and developing countries: An analytic study. AED/LearnLink, Pages: 116, http://pdf.usaid. gov/pdf_docs/PNACM294.pdf.

Heinrichs, N. and S.G. Hofmann, 2001. Information processing in social phobia: A critical review. Clin. Psychol. Rev., 21: 751-770.

Holloway, S.L. and G. Valentine, 2003. Cyberkids: Children in the Information Age. RoutledgeFalmer, London, ISBN-13: 9780415230582.

Jackson, L.A., K.S. Ervin, P.D. Gardner and N. Schmitt, 2001. Gender and the internet: Women communication and men searching. Sex Roles, 44: $363-379$.

Joiner, R., J. Gavin, J. Duffield, M. Brosnan and C. Crook et al., 2005. Gender, internet identification and internet anxiety: Correlates of internet use. CyberPsychol. Behav., 8: 371-378.

Liverpool, S., 2002. Women, information and technology (ICT) and education. An analysis of the May, 1998 internship Program at University of Jos, Nigeria.

Liverpool, S., 2004. Women and the development of Information and Communication Technology (ICT) in Nigeria: A case study of two Nigerian Universities. Master's Thesis, University of Iowa, Iowa City, Iowa, United States.
Nwajiuba, C.A. and E.A. Ukwandu, 2007. Female ICT participation in South-East Nigerian tertiary Institutions: Inhibiting factors. J. Niger. Acad. Edu., 3: 21-31.

Olubamise, B. and J. Awe, 2007. A synopsis of the ICT4D sector in Nigeria incorporating activities of the Government, private sector and non-governmental organizations: ICT4D annual review 2007. [online] http://www.jidaw.com/itsolutions/ict4dreview2007. html [accessed 19.02.11].

Opie, C., 1998. Whose Turn Next? Gender Issues in Information Technology. In: Gender in the Secondary Curriculum: Balancing the Books, Clark, A. and E. Millard (Eds.). Routledge, London, ISBN: 9780415167024, pp: 81-96.

Rapee, R.M., and R.G. Heimberg, 1997. A cognitivebehavioral model of anxiety in social phobia. Behav. Res. Therapy, 35: 741-756.

Turner, S. V., P.W. Bernt and N. Pecora, 2002. Why women choose information technology careers: Educational, social and familial influences. Proceedings of the Annual Meeting of the American Educational Research Association, April 1-5, 2002, New Orleans, LA., USA., pp: 1-20.

UCLA, 2004. World internet project. UCLA Centre for Communication Policy, Los Angeles.

Vikas, N., 2003. Empowerment and governance through information and communication technologies: Women's perspective. London School of Economics, UK. 